\title{
Epistemologia da Ciência da Informação: evolução da pesquisa e suas bases referenciais
}

Marivalde Moacir Francelin

\begin{abstract}
Doutorado em Ciência da Informação pela Universidade de São Paulo. Professor do curso de Biblioteconomia e do Programa de Pós-graduação em Ciência da Informação da Universidade de São Paulo
\end{abstract}

http://dx.doi.org/10.1590/1981-5344/3135

A presente pesquisa analisa a evolução da produção científica sobre epistemologia na área de Ciência da Informação. Também apresenta autores de destaque e principais referenciais usados nos artigos selecionados. Pergunta se o aumento das publicações de artigos sobre epistemologia pode significar a consolidação de uma comunidade de pesquisa. Por extensão, destaca a possibilidade de identificar tradições filosóficas e científicas através dos referenciais do corpus de análise. Defende a hipótese de que o aumento da produção sobre epistemologia em Ciência da Informação indica o reconhecimento e a relevância desta temática nos últimos anos. Os levantamentos foram realizados em 30 periódicos científicos da Ciência da Informação, no período de 1972 a 2015. No total, 164 artigos foram selecionados para análise. A distribuição dos artigos selecionados evidenciou o aumento significativo da pesquisa a partir de 2004. Diante do aumento da produção, o quadro geral de autores e referenciais se destaca pela tradição, pluralidade e atualização constante de seus pontos de vista. Ressalta a necessidade de incentivar o caráter espontâneo das pesquisas sobre 0 tema no universo da graduação e da pós-graduação. Conclui que há um indicativo de consolidação da pesquisa e, principalmente, a formação de uma comunidade científica em torno da epistemologia na Ciência da Informação. 
Palavras-chave: Epistemologia; Paradigmas; Ciência da Informação; Produção científica; Pesquisa.

\section{Epistemology of Information Science: evolution of research and its referencial bases}

The present research analyzes the evolution of scientific production on the epistemology in the area of Information Science. It also seeks to present prominent authors and the main referencials used in the selected articles. Asks whether the increase in the number of articles publications on epistemology can mean the consolidation of a research community. By extension, presents the possibility of identifying philosophical and scientific traditions through the referencials of a corpus of analysis. It defends the hypothesis that the increase of the production on epistemology in Information Science indicates the recognition and relevance of this subject in the last years. Surveys were carried out in 30 scientific journals of Information Science, from 1972 to 2015, and 164 articles were selected for the analysis. The distribution of selected articles evidenced a significant increase in research from 2004. Faced with the increase in production, the general framework of authors and referencials stands out for the tradition, plurality and constant updating of their points of view. Highlights the need to encourage the spontaneous nature of research on the subject in the universe of undergraduate and postgraduate studies. It concludes that there is an indicative of consolidation of the research and, mainly, the formation of a scientific community around the epistemology of Information Science.

Keywords: Epistemology; Paradigms; Information Science; Scientific production; Research.

Recebido em 18.06.2018 Aceito em 13.07.2018

\section{Introdução: epistemologias e bases referenciais}

A emergência de novos contextos paradigmáticos, conforme observado por Saracevic (1996), Pinheiro (1999), Aquino (2002), Capurro (2003) e Robredo (2003), pode ter sido uma das características que motivou o aumento das pesquisas epistemológicas na Ciência da 
Informação. Especificamente, o amadurecimento científico, o desenvolvimento de programas e grupos de pesquisa, o apoio institucional e a maior participação da comunidade nas esferas científicas, além do aprimoramento na produção científica, podem ser igualmente destacados nessa evolução.

$\mathrm{Na}$ sequência, outras pesquisas demonstraram que a temática ganhou importância como objeto de estudo (MENEZES, 2013; RABELLO, 2012; SILVA, 2011; SOUZA, 2011; ARBOIT; BUFREM; FREITAS, 2010; FREIRE, 2008; ARAUJO et al., 2007; RENAULT, 2007a). Em linhas gerais, as pesquisas que compreendem a epistemologia como um objeto de estudo da Ciência da Informação identificam correntes teóricas, analisam relações entre autores e levantam literatura sobre o tema.

Do contato com esses estudos surgiu a necessidade de atualização dos dados sobre a produção e a identificação de suas bases referenciais. Esta pesquisa, portanto, teve como principal objetivo a análise da evolução da produção científica sobre a epistemologia na área de Ciência da Informação. Por extensão, apresenta os autores que se destacaram como os principais referenciais usados nos artigos selecionados.

Mapear a epistemologia na pesquisa pode ser o mesmo que tentar saber como o termo "epistemologia" é usado na Ciência da Informação. Se este é um caminho possível, então é aceitável dizer que o uso de um termo leva ao entendimento do seu significado. Portanto, quando se fala em pesquisar como o termo epistemologia está sendo usado, talvez seja o mesmo que perguntar pelo seu significado. O uso de termos e de conceitos pode ser verificado através da análise do discurso e da linguagem ou mediante a aplicação de outros recursos metodológicos. Neste caso, os usos do termo "epistemologia" podem estar fundamentados, para além da palavra, em conhecimento conceitual, legitimado em atores, autores, disciplinas e pesquisa.

$\mathrm{Na}$ perspectiva metodológica escolhida o significado de um termo pode ser determinado por uma corrente teórica. Teorias fazem parte de paradigmas e estes se relacionam com uma série de filósofos, cientistas e pesquisadores. Como existem diversas teorias no mesmo paradigma (RENAULT, 2007b), a epistemologia tem vários sentidos. A existência de diversas correntes teóricas caracteriza as epistemologias contemporâneas (MOREIRA; MASSONI, 2011). No contexto dessas epistemologias muitos filósofos e cientistas se dedicaram ao estudo do conhecimento. Como exemplo, pode-se mencionar Kuhn (2001), no campo das revoluções científicas, Feyerabend (2007), na defesa do anarquismo teórico e metodológico, e Morin (1999), com a teoria do pensamento complexo e a religação dos saberes.

De um ponto de vista ampliado, racionalistas, como René Descartes, Baruch Spinoza, Gottfried W. Leibniz e Immanuel Kant, e empiristas, como John Locke, George Berkeley e David Hume, são parte da tradição e das bases referenciais da epistemologia. Além do racionalismo e do empirismo, ceticismo, realismo, fundacionalismo, coerentismo, positivismo, behaviorismo, naturalismo, pragmatismo, internalismo, 
externalismo e intuicionismo são outros exemplos do pensamento epistemológico (DUTRA, 2010; GRECO; SOSA, 2008; DANCY, 1990).

A identificação de bases referenciais, conforme exemplos de González de Gómez (2013), Santarem Segundo, Silva e Mostafa (2012), Fernandes e Saldanha (2012), Araújo et al. (2009; 2010), Robredo (2007), Matheus (2005), pode ser, do mesmo modo, uma tradição na Ciência da Informação. Isto faz com que a produção epistemológica na Ciência da Informação seja retomada para novas análises e discussões.

O desenvolvimento da comunidade científica no campo epistemológico da Ciência da Informação sugere a continuidade nas relações entre seus atores. Mensurar com exatidão tais relacionamentos é difícil, mas é possível dar consistência para algumas hipóteses de pesquisa.

Nesse sentido, esta pesquisa parte da hipótese de que a produção científica sobre o tema epistemologia na área de Ciência da Informação aumentou. A segunda hipótese indica que os referenciais usados pelos pesquisadores são um ponto de partida comum e relevante para os estudos epistemológicos na área. Em seu conjunto, os referenciais descrevem os percursos filosóficos e científicos das pesquisas e, principalmente, permitem que se tenha uma visão consistente da multiplicidade paradigmática da Ciência da Informação.

Geralmente, os métodos mais usados para analisar esses percursos buscam reconstruir discursivamente as correntes de pensamento e analisar bibliografias sobre a filosofia, a ciência e a epistemologia do campo. Tais métodos contribuem para o desenvolvimento da Ciência da Informação na medida em que propõem novas relações entre teorias, identificando, dessa forma, a trajetória de uma temática de pesquisa por meio da produção dos pesquisadores.

\section{Procedimentos metodológicos}

Para o exame da situação do tema epistemologia no campo da Ciência da Informação foi realizada uma pesquisa bibliográfica nos periódicos brasileiros da área de Ciência da Informação.

A pesquisa foi realizada no universo online de 30 periódicos com acesso aos textos completos. Como o objetivo é a apresentação de um painel da evolução das pesquisas sobre epistemologia na Ciência da Informação, analisou-se todas as revistas selecionadas. Não houve distinção entre revistas de recente circulação e revistas com maior tempo de publicação. Aplicou-se esse mesmo critério para os periódicos descontinuados, pois, é importante reconhecê-los como parte de uma construção histórica e científica.

A busca usou os termos: epistemologia; epistemológico(s); e, epistemológica(s). Essa busca teve caráter exaustivo, por isso foi feita no campo "todos" dos buscadores das revistas, no período de 1972 a 2015. A seleção dos resultados teve caráter objetivo, relacionando artigos epistemológicos, teóricos e filosófico-científicos. A seleção contou com 164 artigos sobre o tema epistemologia. Apesar das variações nas abordagens 
sobre o tema, trata-se de um número expressivo se comparado com outras temáticas de destaque na Ciência da Informação.

A análise da literatura selecionada privilegiou, na primeira etapa, a distribuição dos artigos nas revistas ao longo das décadas. Na sequência, identificou-se os autores com maior produção sobre o tema. A produção foi dividida por autores e por ano de publicação.

$\mathrm{Na}$ terceira etapa da pesquisa, analisou-se a literatura selecionada do ponto de vista dos seus referenciais, principal tema deste artigo. Os referenciais são as próprias referências bibliográficas dos artigos. Semelhante ao levantamento, esse procedimento foi manual para garantir que a recuperação das referências não fosse prejudicada por falta de padronização. A seguir, são apresentados os resultados e a discussão da pesquisa.

\section{Resultados}

No Gráfico 1 é possível verificar a criação de um número significativo de revistas nas décadas de 1990 e 2000, 16 no período. $\mathrm{Na}$ década de 1970, cinco revistas apareceram, sendo que duas (Cadernos de Biblioteconomia e Revista de Biblioteconomia de Brasília) encerraram suas edições, respectivamente, nas décadas de 1980 e 2000. Lembrando que a Revista da Escola de Biblioteconomia da UFMG passou a se chamar, na década de 1990, Perspectivas em Ciência da Informação. Na década de 1980 mais cinco revistas foram criadas na área, sendo que duas delas (Estudos Avançados em Biblioteconomia e Ciência da Informação e Revista de Biblioteconomia \& Comunicação) tiveram suas edições descontinuadas nas décadas de 1980 e 2000. Na década de 1990, oito revistas apareceram e apenas uma (Revista Eletrônica Informação e Cognição) teve a edição descontinuada em 2000.

Gráfico 1 - Criação de periódicos de Ciência da Informação no período de 1972 a 2015

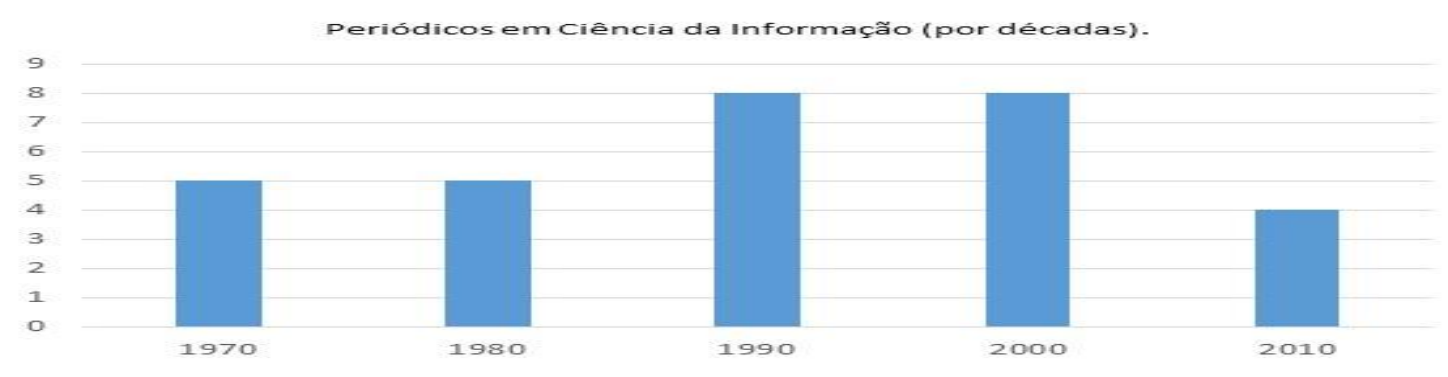

Fonte: Dados da pesquisa.

Oito revistas surgiram em 2000 e todas continuavam ativas no momento dos levantamentos. No início da década de 2010 novas revistas apareceram, indicando a tendência de ampliação do escopo das revistas científicas na área de Ciência da Informação no Brasil. Entre 2010 e 2015 outras quatro revistas iniciaram suas publicações. Como se pode observar, das 30 revistas apenas 5 tiveram suas edições descontinuadas (duas da 
década de 1970, duas da década de 1980 e uma da década de 1990). Porém, seguindo a tendência das duas décadas anteriores, é possível dizer que o número de revistas aumentará nos próximos anos.

De acordo com o Gráfico 2, seis revistas (Ágora: revista do Arquivo Público do Estado de Santa Catarina \& Curso de Arquivologia da UFSC; Biblionline; Biblos: Revista do Instituto de Ciências Humanas e da Informação; Cadernos de Biblioteconomia; Estudos Avançados em Biblioteconomia e Ciência da Informação; Revista de Biblioteconomia \& Comunicação) não tiveram artigos recuperados.

Gráfico 2 - Número de publicações de artigos sobre epistemologia nos periódicos da área (1972-2015)

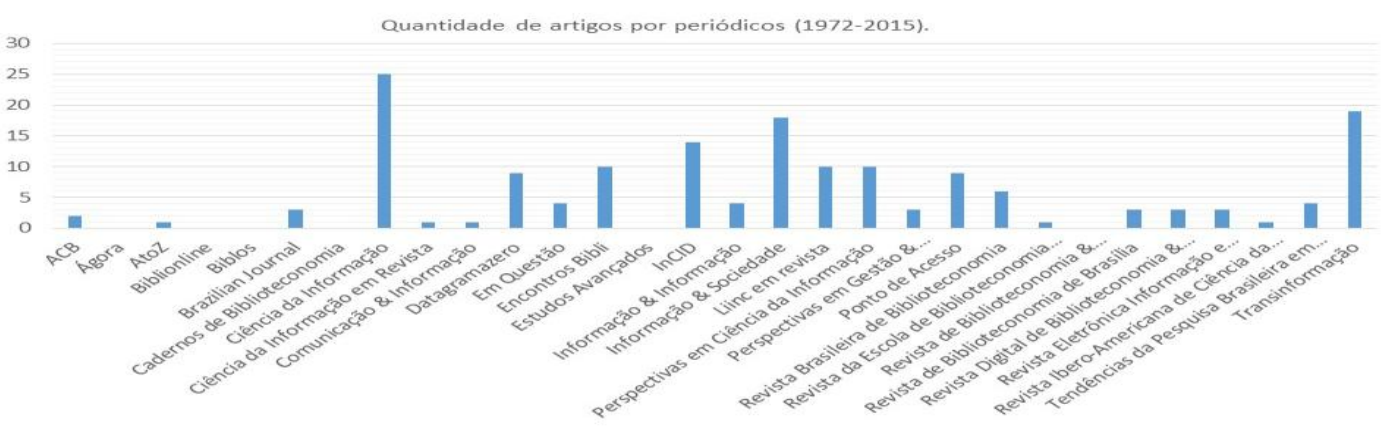

Fonte: Dados da pesquisa.

Das 30 revistas analisadas, 24 apresentaram pelo menos 1 artigo sobre epistemologia. A revista com maior número de artigos recuperados foi a Ciência da Informação, 25 no total. Na sequência, estão as revistas Transinformação, com 19 artigos, e Informação \& Sociedade, com 18 artigos. A revista InCID vem a seguir, com 14 artigos, e três revistas, Encontros Bibli, Liinc em Revista e Perspectivas em Ciência da Informação, aparecem com 10 artigos cada.

Analisando somente as revistas que publicaram artigos sobre o tema no período de 2010 a 2015, verificou-se, conforme o Gráfico 3, que o surgimento de outras revistas permitiu uma melhor distribuição da produção.

Gráfico 3 - Distribuição dos artigos nos periódicos. Últimos cinco anos - de 2010 a 2015

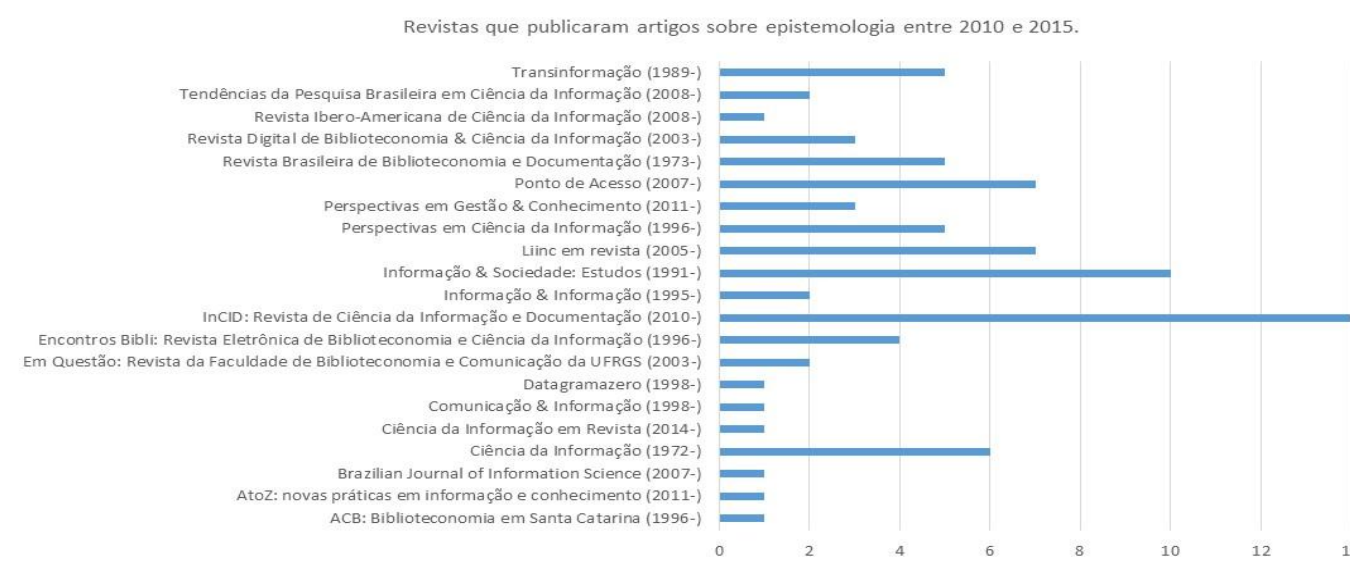


Fonte: Dados da pesquisa.

Três exemplos são: a revista InCID: Revista de Ciência da Informação e Documentação, que começou a ser publicada em 2010 e conta com 14 artigos publicados relacionados ao tema; a revista Informação \& Sociedade, com 10 artigos; e, a revista Ponto de Acesso, com 7 artigos.

Outro ponto que pode ser destacado é que, dos 164 artigos selecionados, a publicação de 81 deles ocorreu entre 2010 e 2015, ou seja, quase a metade da produção sobre epistemologia.

Para que seja possível visualizar e desenvolver algumas observações mais específicas, o Gráfico 4 apresenta a evolução da publicação de artigos no período de 1972 a 2015. Em 1973 e 1974 apareceram as duas primeiras publicações sobre epistemologia na Ciência da Informação. Depois desse período é possível identificar alguns intervalos temporais. 0 maior intervalo sem publicações de artigos sobre epistemologia foi de 5 anos, de 1982 a 1987. De 1972 a 2002 a média representou menos de 1 artigo por ano, somando um total de 24 artigos no período. Muito pouco para uma área das Ciências Humanas. Mas, a partir do ano de 2002, notou-se o aumento substancial da quantidade de artigos sobre epistemologia nas revistas brasileiras de Ciência da Informação.

Gráfico 4 - Evolução da publicação de artigos científicos sobre epistemologia em revistas brasileiras de Ciência da Informação (19722015)

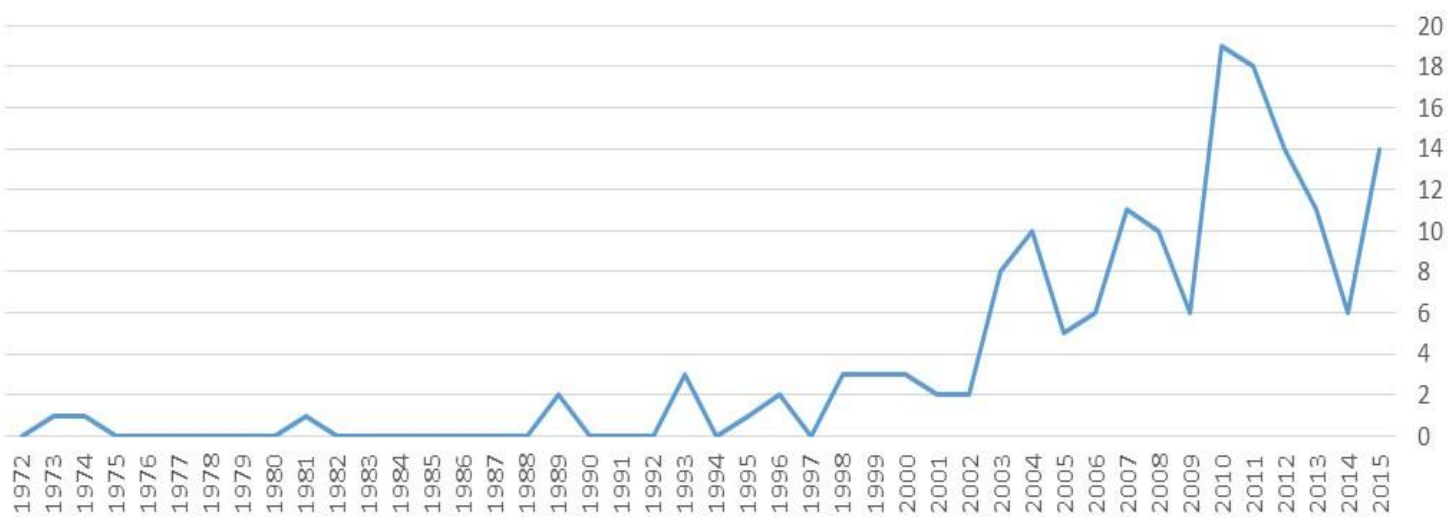

Fonte: Dados da pesquisa.

Pode-se verificar que o número de artigos evoluiu de 2 ou 3, entre 1998 e 2002, para 8 ou 10 em 2003 e 2004. Trata-se de três vezes mais artigos do que até então era publicado anualmente. Após o ano de 2002, as publicações aconteceram com mais regularidade, ganhando destaque os anos de 2004, quando se publicou 10 artigos, de 2007, com 12 artigos, de 2010, com 19 artigos, de 2011, com 18 artigos e de 2015, com 14 artigos.

O Gráfico 5 apresenta os autores com maior número de artigos publicados nas revistas analisadas. 
Gráfico 5 - Autores com três ou mais artigos recuperados na temática "epistemologia" no período analisado (1972-2015)

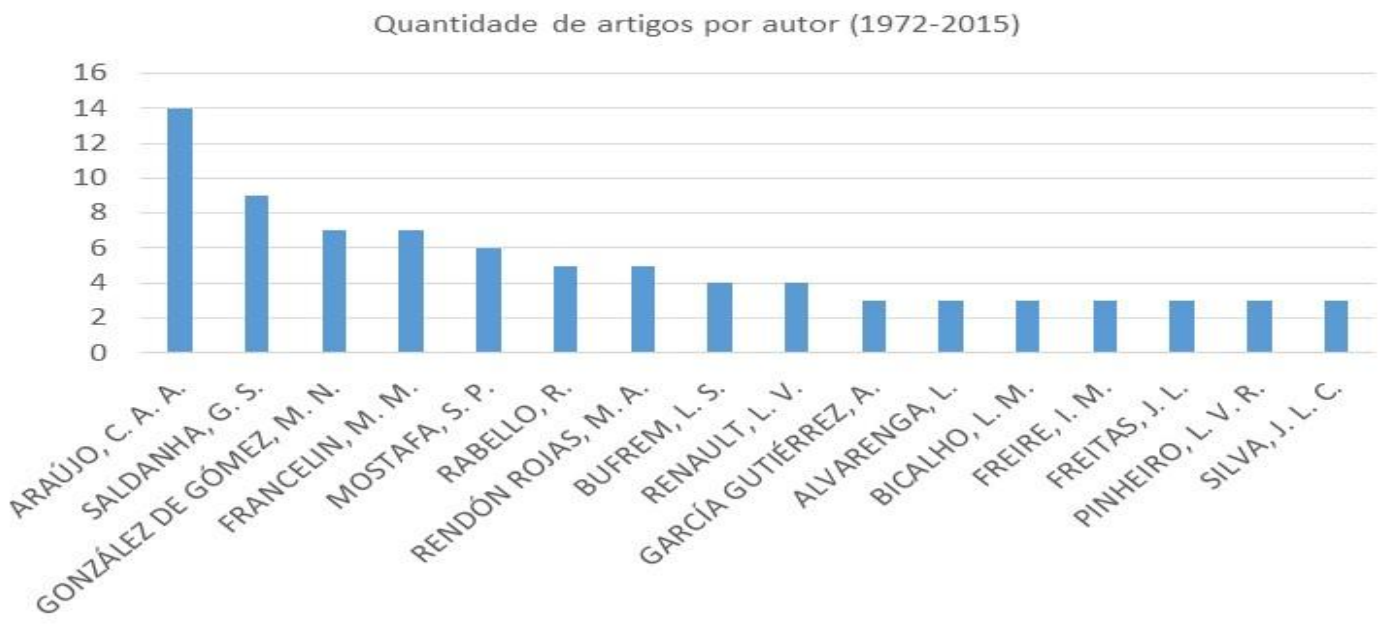

Fonte: Dados da pesquisa.

De acordo com o Gráfico 5, 16 autores publicaram 3 ou mais artigos entre 1972 e 2015. Numa visão geral, 21 autores figuraram em 2 artigos e 122 em apenas 1 artigo.

No período analisado, Carlos Alberto Ávila Araújo (ARAúJO, C. A. A.) foi o autor com maior número de artigos recuperados: 14 no total. Com 9 artigos, Gustavo Silva Saldanha (SALDANHA, G. S.) apareceu logo em seguida. Na sequência, estão Maria Nélida González de Gómez (GONZÁLEZ DE GOMEZ, M. N.) e Marivalde Moacir Francelin (FRANCELIN, M. M.), com 7 artigos cada. Solange Puntel Mostafa tem 6 artigos. Aparecem, com 5 artigos, os autores Rodrigo Rabello (RABELLO, R.) e Miguel Ángel Rendón Rojas (RENDÓN ROJAS, M. A.). Leilah Santiago Bufrem (BUFREM, L. S.), Antonio García Gutiérrez (GARCÍA GUTIÉRREZ, A.) e Leonardo Vasconcelos Renault (RENAULT, L. V.) estão com 4 artigos cada. Encerrando a descrição do gráfico, com 3 artigos cada, estão as autoras Lídia Alvarenga (ALVARENGA, L.), Lucinéia Maria Bicalho (BICALHO, L. M.), Isa Maria Freire (FREIRE, I. M.), Juliana Lazzarotto Freitas (FREITAS, J. L.), Lena Vania Ribeiro Pinheiro (PINHEIRO, L. V. R.) e o autor Jonathas Luiz Carvalho Silva (SILVA, J. L. C.).

Os autores Miguel Ángel Rendón Rojas (RENDÓN ROJAS, M. A.) e Antonio García Gutiérrez (GARCÍA GUTIÉRREZ, A.) não são pesquisadores brasileiros, mas publicaram nos periódicos analisados e têm relevante influência nas pesquisas da área. Como mencionado na introdução, é possível atualizar os quadros de produção levando em consideração os recortes e as metodologias usados em cada estudo. Nota-se, com base nas pesquisas de Arboit, Bufrem e Freitas (2010), Freire (2008) e Araújo et al (2007), certa regularidade nesse quadro de produção, isto é, existem autores que aparecem recorrentemente, mesmo em estudos distintos.

A identificação das bases referenciais dos artigos selecionados fez parte da terceira etapa da pesquisa. Identificou-se 5.375 referências bibliográficas em 160 artigos do corpus de análise. Apenas 4 artigos não 
tiveram suas referências recuperadas por falta de acesso ou porque não identificaram, com clareza, suas fontes. Numa perspectiva quantitativa pode-se falar em uma média de 32 citações por artigo. Aparentemente é um número considerável de citações, porém, como a maioria dos artigos é de base teórica, a quantidade reflete o recurso metodológico da revisão bibliográfica.

As 5.375 referências estão distribuídas em 2.271 autores (Gráfico $6)$.

Gráfico 6 - Distribuição do número de citações por autor nos artigos selecionados

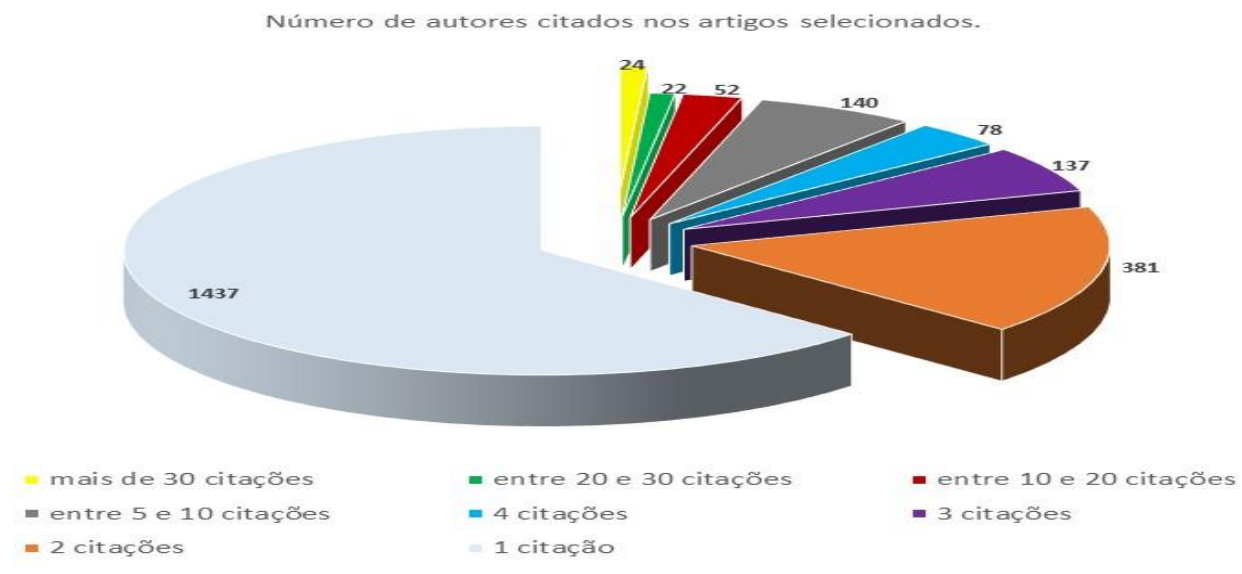

Fonte: Dados da pesquisa.

Do total de 2.271 autores, 24 tiveram mais de 30 citações. Já, 22 autores tiveram entre 20 e 30 citações. Outros 52 autores ficaram entre 10 e 20 citações. O intervalo de 5 a 10 citações apresentou 140 autores. Finalizando a descrição do gráfico: 78 autores foram citados quatro vezes; 137, três vezes; 381, duas vezes; e, 1.437, uma vez.

A quantidade de autores citados apenas uma vez indica que há considerável distribuição em relação a outros referenciais. São 1.437 referências que não se repetiram em 160 artigos. Isso indica uma predisposição para analisar paradigmas diversos numa literatura ampla e multifacetada.

Existem motivos para acreditar que essa literatura referencial tem contribuído, no sentido de estimular e motivar, para a exploração de novas abordagens epistemológicas. O perfil da condução não-determinista e anti-dogmática é nuclear nos textos referenciais identificados na análise. A ênfase nas vantagens do pensamento que reúne e não isola é convertida em método de pesquisa, resultando em painéis e mapas relacionais de conhecimento. Esses painéis e mapas figuram como avanços de fronteiras e atualizações de hipóteses sobre o pensamento filosófico-científico em geral e, especificamente, sobre a epistemologia na Ciência da Informação. Em síntese, existe uma tradição construída com o objetivo de estimular o pensamento sobre informação e conhecimento nas múltiplas instâncias dos saberes. 
A seguir, o Gráfico 7 apresenta os autores com mais de 50 citações. Maria Nélida González de Gómez (GONZÁLEZ DE GÓMEZ, M. N.) teve o maior número de citações: 126. Na sequência, estão Rafael Capurro (CAPURRO, R.), com 110 citações, Tefko Saracevic (SARACEVIC, T.), com 85, Lena Vania Ribeiro Pinheiro (PINHEIRO, L. V. R.), com 83, Gernot Wersig (WERSIG, G.), com 67, Jesse Hauk Shera (SHERA, J. H.), com 66, Bernd Frohmann (FROHMANN, B.), com 58, Edgar Morin (MORIN, E.), com 53, Michael K. Buckland (BUCKLAND, M. K.), com 52, e Birger Hjørland (HJØRLAND, B.), com 51 citações.

Gráfico 7 - Autores com mais de 50 citações na literatura periódica sobre epistemologia em Ciência da Informação (1972-2015)

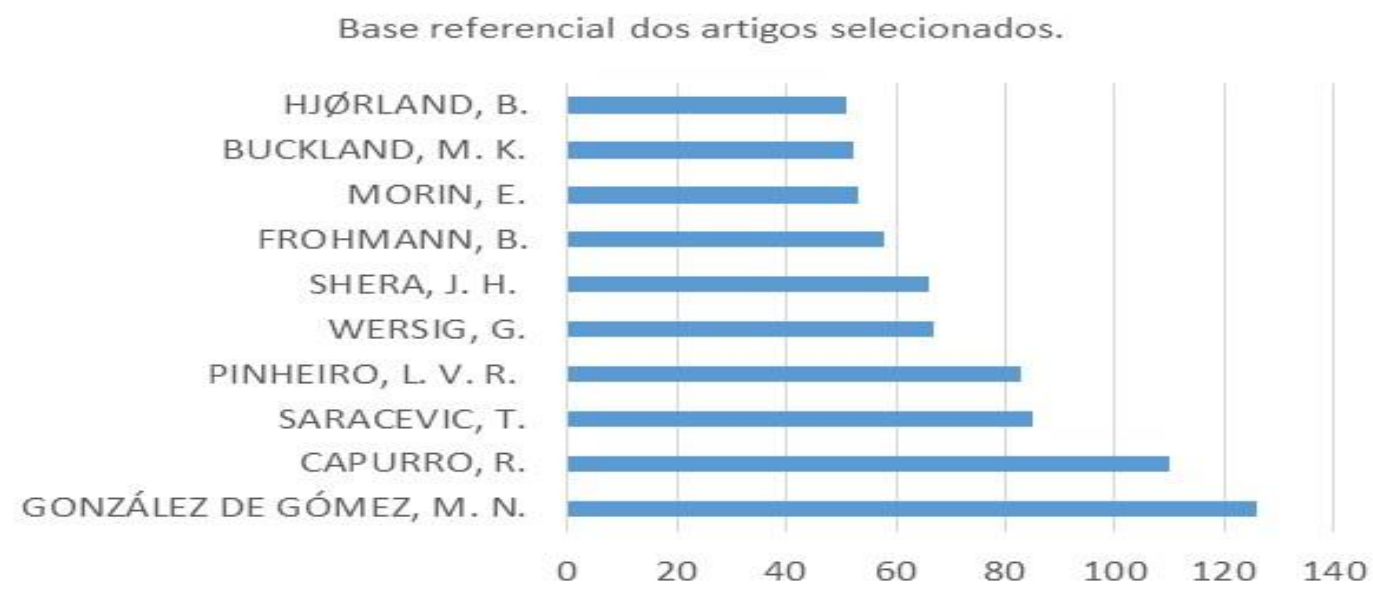

Fonte: Dados da pesquisa.

Como indicado no início deste artigo, diversos desses autores figuraram em outros estudos da área. Porém, em conjunto, representam as bases referenciais da epistemologia na Ciência da Informação. A análise dos resultados deve levar em consideração que a quantidade exata de citações pode variar por causa do período de recorte, das revistas e da forma de busca. Mesmo assim, é possível afirmar que existe consenso de que as bases referenciais, indicadas no Gráfico 7, representam uma tradição consolidada nas pesquisas teóricas, epistemológicas e interdisciplinares da Ciência da Informação.

\section{Discussão}

Em sua totalidade, os resultados demonstram o aumento do número de artigos sobre epistemologia, evidenciando tendências da pesquisa e do conhecimento produzido na Ciência da Informação. Artigos científicos podem aparecer de tempos em tempos sem a necessária relação, por exemplo, com pesquisas de mestrado ou de doutorado. Se existe produção com essas características, é evidente que pesquisas epistemológicas na Ciência da Informação deixaram de ser esporádicas e individualizadas para serem permanentes e coletivas. 
A epistemologia é uma temática de estudo e pesquisa que não está restrita ao campo da formação científica. Isso quer dizer que, quando se fala em epistemologia, o interesse está em ultrapassar fronteiras disciplinares, em subverter metodologias e em tornar os paradoxos evidentes. O conhecimento filosófico-científico chegou até aqui porque manteve, como essência, tais motivações e interesses espontâneos ${ }^{1}$.

A quantificação da produção científica fortalece a hipótese do interesse coletivo e espontâneo sobre o tema epistemologia na Ciência da Informação. Aspectos específicos da análise de citações como, por exemplo, a autocitação, cederam lugar para a segunda possibilidade, que é a da permanência da tradição nos estudos epistemológicos em Ciência da Informação.

Da mesma forma, essa produção parece evidenciar apoio aos pesquisadores que se dedicam à investigação epistemológica. Mesmo que tardiamente, parece que os departamentos de graduação e os programas de pós-graduação da área de Ciência da Informação reconheceram a importância dos estudos sobre a construção do conhecimento filosófico e científico na perspectiva informacional.

Verificou-se que existe uma produção continuada sobre o tema no decorrer das últimas décadas. As publicações podem ser o resultado de projetos de pesquisa sobre epistemologia. Isso é importante porque traz para a área um novo olhar sobre o movimento epistemológico.

A formação da comunidade científica em torno do tema epistemologia em Ciência da Informação consolida, não apenas uma, mas diversas linhas de pesquisa na área. Quando se fala em linhas de pesquisa na área, significa que existem fluxos, não somente de produção de artigos, teses, dissertações, capítulos, livros e trabalhos de eventos, mas de formação de novos pesquisadores. Na medida em que os pesquisadores que fazem parte dos programas de pós-graduação em Ciência da Informação estudam sistematicamente a epistemologia, eles influenciam investigadores em início de carreira, especialmente, no mestrado e no doutorado.

Na pós-graduação, a pergunta pela realização de trabalhos, como teses e dissertações, é inevitável, mas outras indagações sobre disciplinas, linhas e grupos de pesquisa precisam de atenção porque não se deve falar apenas de produção científica e sim de formação e, por extensão, de paradigmas científicos.

Acredita-se que novas culturas científicas estejam se formando sobre os estudos epistemológicos na Ciência da Informação. E, como quase toda tradição na história da ciência, a da Ciência da Informação igualmente começa com muitas experimentações teóricas. É fundamental que isso ocorra para evidenciar os possíveis campos de tendência, atuação e investigação.

\footnotetext{
${ }^{1}$ O termo "espontâneo" está sendo usado como algo não imposto ou feito sob demanda, isto é, que acontece voluntariamente. Para Mario Bunge, a ciência, em especial a básica, deve ser feita para o "povo" e de forma voluntária. Segundo Bunge (1980, p. 69, grifo do autor), "[...] todo bom cientista faz ciência para o povo, voluntariamente."
} 


\section{Considerações finais}

Todos as informações levantadas indicam a evolução, no cenário teórico, filosófico e científico, dos estudos epistemológicos na Ciência da Informação. Nesse sentido, a pesquisa não se pautou unicamente pela indicação de frequência das publicações. As informações coletadas tiveram como último, e mais importante objetivo, mostrar a importância de se estabelecer grupos, linhas e disciplinas de pesquisa e ensino voltados para a teoria, a filosofia e a epistemologia na Ciência da Informação. Uma ciência interdisciplinar como a Ciência da Informação não pode ficar à margem dos estudos teóricos, filosóficos e científicos.

Se há carência de matérias conceituais e reflexivas, isso deve ser objeto de novas análises, especialmente na perspectiva de uma indissociável relação entre teoria e prática, saber e fazer, ciência básica e ciência aplicada e entre outras tantas relações possíveis e necessárias para a criação, a construção, o desenvolvimento e a manutenção da própria racionalidade. Na história do pensamento, a razão pressupõe que essas relações e problematizações de perspectivas, no sentido de pontos de vista distintos e fundamentados, sejam analisadas, estimuladas e aprimoradas.

Os momentos de análise deveriam refletir a importância da complexidade no universo do pensamento e indicar processos de construção e desenvolvimento de conhecimento. Não há, mesmo que esta seja uma hipótese provável, um período específico de crise da razão. A razão quase sempre esteve em crise em seus momentos de evolução e, por isso, qualquer movimento que dissemine paradigmas falsos e falaciosos, visando unicamente eliminar dicotomias, contradições, desordens e complexidades, merece atenção e crítica. Como mencionado, desordens e complexidades são essenciais ao pensamento espontâneo. Seguindo esta tradição do pensamento espontâneo, a pesquisa verificou que os autores mais citados no corpus de análise cultivam o espírito da pluralidade epistemológica e da natureza complexa do pensamento, respeitando a liberdade das formas de pensar a informação e o conhecimento.

\section{Referências}

AQUINO, M. de A. (Org.). O campo da Ciência da Informação: gênese, conexões e especificidades. João Pessoa: Editora Universitária/UFPB, 2002.

ARAÚjO, C. A. Á. et al. A Ciência da Informação na visão dos professores e pesquisadores brasileiros. Informação \& Sociedade, João Pessoa, v. 17, n. 2, p. 95-108, maio/ago. 2007. Disponível em: <http://www.ies.ufpb.br/ojs2/index.php/ies/article/view/637>. Acesso: 11 fev. 2016.

ARAÚjO, C. A. Á. et al. A contribuição de F. W. Lancaster para a Ciência da Informação no Brasil. Ponto de Acesso, v. 3, n. 2, p. 132-146, ago. 
2009.

<http://www.portalseer.ufba.br/index.php/revistaici/article/view/3355/26 14>. Acesso: 19 fev. 2016.

ARAÚjO, C. A. Á. et al. A contribuição de J. H. Shera para a Ciência da Informação no Brasil. Revista ACB: Biblioteconomia em Santa Catarina, Florianópolis, v. 15, n. 2, p. 71-89, jul./dez. 2010. Disponível em: <http://revista.acbsc.org.br/racb/article/view/712/pdf_35>. Acesso em: 18 fev. 2016.

ARBOIT, A. E.; BUFREM, L. S.; FREITAS, J. L. Configuração epistemológica da Ciência da Informação na literatura periódica brasileira por meio de análise de citações (1972-2008). Perspectivas em Ciência da Informação, v. 15, n. 1 , p. 18-43, jan./abr. 2010. Disponível em: <http://www.scielo.br/scielo.php?script=sci_abstract\&pid=S141399362010000100003\&lng=pt\&nrm=iso\&tlng=pt>. Acesso: 11 fev. 2016.

BUNGE, M. Luxo ou necessidade? In: BUNGE, M. Ciência e desenvolvimento. Tradução de Cláudia Regis Junqueira. Belo Horizonte: Itatiaia, 1980. p. 65-70.

CAPURRO, R. Epistemologia e Ciência da Informação. In: ENCONTRO NACIONAL DE PESQUISA EM CIÊNCIA DA INFORMAÇÃO, 2003, Belo Horizonte. Anais... Belo Horizonte: ENANCIB, 2003. p. 1-21. Disponível em: <http://www.capurro.de/enancib_p.htm>. Acesso em: 12 jun. 2016.

DANCY, J. Epistemologia contemporânea. Tradução de Teresa Louro Pérez. Lisboa: Edições 70, 1990.

DUTRA, L. H. de A. Introdução à epistemologia. São Paulo: Editora Unesp, 2010.

FERNANDES, G. C.; SALDANHA, G. S. Contribuições de Marteleto e González de Gómez ao entendimento do informacional: diálogos com três aportes da informação. Ponto de Acesso, Salvador, v. 6, n. 1, p. 2-31, abr. $2012 . \quad$ Disponível em: <http://www.portalseer.ufba.br/index.php/revistaici/article/view/5413/43 43>. Acesso em: 12 fev. 2016.

FEYERABEND, P. Contra o método. Tradução de Cezar Augusto Mortari. São Paulo: Editora Unesp, 2007.

FREIRE, I. M. Um olhar sobre a produção científica brasileira na temática epistemologia da Ciência da Informação. Tendências da Pesquisa Brasileira em Ciência da Informação, v. 1, n. 1, p. 1-31, 2008. Disponível em: <http://inseer.ibict.br/ancib/index.php/tpbci/article/view/9>. Acesso em: 11 fev. 2016.

GONZÁLEZ DE GÓMEZ, M. N. Luciano Floridi e os problemas filosóficos da informação: da representação à modelização. InCID: Revista de Ciência da Informação e Documentação, Ribeirão Preto, v. 4, n. 1, p. 3-25, jan./jun. 2013. 
<http://www.revistas.usp.br/incid/article/view/59099>. Acesso em: 11 fev. 2016.

GRECO, J.; SOSA, E. (Org.). Compêndio de epistemologia. Tradução: Alessandra Siedschlag Fernandes e Rogério Bettoni. São Paulo: Edições Loyola, 2008.

KUHN, T. S. A estrutura das revoluções científicas. Tradução: Beatriz Vianna Boeira e Nelson Boeira. 6. ed. São Paulo: Perspectiva, 2001.

MATHEUS, R. F. Rafael Capurro e a filosofia da informação: abordagens, conceitos e metodologias de pesquisa para a Ciência da Informação. Perspectivas em Ciência da Informação, Belo Horizonte, v. 10, n. 2, p. 140-165, jul./dez. 2005. Disponível em: <http://portaldeperiodicos.eci.ufmg.br/index.php/pci/article/view/341>. Acesso em: 11 fev. 2016.

MENEZES, I. P. de. A Ciência da Informação: uma reflexão sobre suas bases epistemológicas. 2013. 105f. Dissertação (Mestrado em Gestão) Universidade Federal da Paraíba, João Pessoa, 2013. Disponível em: $<$ http://tede.biblioteca.ufpb.br/bitstream/tede/5893/1/ArquivoTotalIvandr o.pdf>. Acesso em: 1 mar. 2017.

MOREIRA, M. A.; MASSONI, N. T. Epistemologias do século XX: Popper, Kuhn, Lakatos, Laudan, Bachelard, Toulmin, Feyerabend, Maturana, Bohn, Bunge, Prigogine, Mayr. São Paulo: E.P.U, 2011.

MORIN, E. O método 3: o conhecimento do conhecimento. Tradução de Juremir Machado da Silva. 2. ed. Porto Alegre: Sulina, 1999.

PINHEIRO, L. V. R. (Org.). Ciência da Informação, Ciências Sociais e interdisciplinaridade. Rio de Janeiro: IBICT, 1999.

RABELLO, R. A Ciência da Informação como objeto: epistemologias como lugares de encontro. Perspectivas em Ciência da Informação, Belo Horizonte, v. 17, n. 1, p. 2-36, jan,/abr. 2012. Disponível em: <http://portaldeperiodicos.eci.ufmg.br/index.php/pci/article/view/1107>. Acesso em: 1 mar. 2017.

RENAULT, L. V. A Ciência da Informação e sua configuração epistemológica: análise com base nas linhas de pesquisa da área. 2007. 165f. Dissertação (Mestrado em Ciência da Informação) - Escola de Ciência da Informação, Universidade Federal de Minas Gerais. Belo Horizonte, 2007a. Disponível em: <http://www.bibliotecadigital.ufmg.br/dspace/bitstream/handle/1843/VAL A-74QJ66/mestrado__leonardo_vasconcelos_renault.pdf?sequence $=1>$. Acesso em: 4 ago. 2016.

RENAULT, L. V. Paradigmas e modelos: proposta de análise epistemológica para a Ciência da Informação. Informação \& Sociedade: Estudos, João Pessoa, v. 17, n. 2, p. 53-60, maio/ago. 2007b. Disponível em: $\quad<$ http://www.ies.ufpb.br/ojs2/index.php/ies/article/view/636>. Acesso em: 5 fev. 2016. 
ROBREDO, J. Da Ciência da Informação revisitada aos sistemas humanos de informação. Brasília: Thesaurus, 2003.

ROBREDO, J. Filosofia da ciência da informação ou Ciência da Informação e filosofia? In: TOUTAIN. Lídia Maria Batista Brandão (Org.). Para entender a Ciência da Informação. Salvador: EDUFBA, 2007. p. 35-73

SANTAREM SEGUNDO, J. E.; SILVA, M. R. da; MOSTAFA, S. P. (Org.). Os pensadores e a Ciência da Informação. Rio de Janeiro: E-papers, 2012.

SARACEVIC, T. Ciência da Informação: origem, evolução e relações. Tradução de Ana Maria P. Cardoso. Perspectivas em Ciência da Informação, Belo Horizonte, v. 1, n. 1, p. 41-62, jan./jun. 1996. Disponível

em:

$<$ http://portaldeperiodicos.eci.ufmg.br/index.php/pci/article/view/235/22

>. Acesso em: 7 mar. 2017.

SILVA, J. L. C. A identidade da Ciência da Informação brasileira no contexto das perspectivas históricas da pós-graduação: análise dos conteúdos programáticos dos PPGCI's. 2011. 229f. Dissertação (Mestrado em Ciência da Informação) - Centro de Ciências Sociais Aplicadas, Universidade Federal da Paraíba. João Pessoa, 2011. Disponível em: < http://tede.biblioteca.ufpb.br/bitstream/tede/3905/1/arquivototal.pdf >. Acesso em: 1 mar. 2017.

SOUZA, E. D. de. A epistemologia interdisciplinar na Ciência da Informação: dos indícios aos efeitos de sentido na consolidação do campo disciplinar. 2011. 346f. Tese (Doutorado em Ciência da Informação) Universidade Federal de Minas Gerais, Escola de Ciência da Informação, Belo Horizonte, 2011.2 Disponível em: <http://www.bibliotecadigital.ufmg.br/dspace/bitstream/handle/1843/ECI D-8P2JNH/epistemologia_interdisciplinar_edivanio.pdf?sequence $=1>$. Acesso em: 7 mar. 2013. 